\title{
Using an e-health intervention to enhance patient visits for hypertension: The nurse practitioner perspective
}

\author{
Jessica Alicea-Planas \\ Fairfield University, jplanas@fairfield.edu \\ Patricia J. Neafsey \\ Elizabeth Anderson
}

Follow this and additional works at: https://digitalcommons.fairfield.edu/nursing-facultypubs Copyright 2012 Maney Publishing for American Medical Writers Association. Post print has been archived with permission. Final published version available http://www.maneyonline.com/ doi/abs/10.1179/1753807612Y.0000000017.

\section{Peer Reviewed}

\section{Repository Citation}

Alicea-Planas, Jessica; Neafsey, Patricia J.; and Anderson, Elizabeth, "Using an e-health intervention to enhance patient visits for hypertension: The nurse practitioner perspective" (2012). Nursing and Health Studies Faculty Publications. 61.

https://digitalcommons.fairfield.edu/nursing-facultypubs/61

\section{Published Citation}

Alicea-Planas, J., Neafsey, P. J., \& Anderson, E. (2012). "Using an e-health intervention to enhance patient visits for hypertension: The nurse practitioner perspective." Journal of Communication in Healthcare, 5(4), 239-249. doi: 10.1179/1753807612Y.0000000017

This item has been accepted for inclusion in DigitalCommons@Fairfield by an authorized administrator of DigitalCommons@Fairfield. It is brought to you by DigitalCommons@Fairfield with permission from the rightsholder(s) and is protected by copyright and/or related rights. You are free to use this item in any way that is permitted by the copyright and related rights legislation that applies to your use. For other uses, you need to obtain permission from the rights-holder(s) directly, unless additional rights are indicated by a Creative Commons license in the record and/or on the work itself. For more information, please contact digitalcommons@fairfield.edu. 


\title{
Using an e-health intervention to enhance patient visits for hypertension: The nurse practitioner perspective
}

\author{
Jessica Alicea-Planas, ${ }^{1,2}$ Patricia J. Neafsey ${ }^{2}$, Elizabeth Anderson ${ }^{2}$ \\ ${ }^{7}$ School of Nursing, Fairfield University, Fairfield, CT, USA \\ ${ }^{2}$ School of Nursing Unit 2026, University of Connecticut, Storrs, CT, USA
}

Correspondence to:
Patricia J. Neafsey,
School of Nursing Unit
2026, University of
Connecticut, Storrs,
CT 06269, USA,
patricia.neafsey@uconn.
edu

\begin{abstract}
This article reports the findings from interviews with 11 nurse practitioners (NPs) who provided an inoffice, e-health intervention as part of a randomized clinical trial aimed at improving medication adherence and reducing adverse self-medication behaviors in older adults with hypertension. The NPs' perspective of their experience with training for the research protocol, recruitment of patient participants, implementing the e-health intervention, and patient response was elicited through open-ended questions in individual face-to-face tape recorded interviews.
\end{abstract}

Keywords: Qualitative research, nurse practitioners, e-health intervention, older adults, communication, hypertension

\section{Introduction}

Monitoring and managing hypertension in older adults accounts for a large time burden for primary care practitioners - resulting in more office visits than any other chronic condition. The Institute of Medicine of the National Academies estimates that $\$ 15.5$ billion healthcare dollars are spent annually on those taking anti-hypertensives and over $\$ 100$ billion dollars annually if preventable adverse drug events and hospitalizations are included in the cost estimates. ${ }^{1}$ Often during routine office visits, primary care providers are unable to conduct appropriate medication reviews that include querying the patient about what other medications and non prescription agents they take and when they take them, assessing self-medication behaviors, and providing individualized patient education to foster medication adherence and reduce adverse self-medication behaviors and potential drug interactions. ${ }^{2}$ Consequently, the Institute of Medicine estimates that $10 \%$ of adverse drug events are attributable to provider/patient communication failure. ${ }^{3}$ Difficulties seeing, hearing, and understanding health information also contribute to the poor health literacy faced by many older adults with hypertension. ${ }^{4,5}$

Tailored computer based interventions have been used to facilitate discussions between provider and patient, ${ }^{6-8}$ and to motivate individuals to improve health behaviors. ${ }^{9}$ However, these studies have primarily used physicians to implement the intervention and focused on areas other than cardiovascular health (i.e. colorectal cancer screening, oncology, healthier eating habits, and quality-of-life assessment).

Nurse practitioners (NPs) are trained to coordinate care for both the acute and chronically ill and provide health education in addition to facilitation of patients' participation in their care. ${ }^{10}$ They have been especially important to primary care and managing the needs of various populations, including the underserved, ${ }^{11,12}$ specialty areas, ${ }^{13}$ and across the life $\operatorname{span}^{14,15}$ and have been effective in overseeing the assessment and treatment of cardiovascular disease. ${ }^{16-18}$

The Personal Education Program - Next Generation (PEP-NG), aimed at older adults with hypertension, was specifically developed for use in primary care settings with NP providers. The PEP-NG is an interactive, web-based application housed on a touchscreen, wireless tablet PC on a height- and angle-adjustable stand (see Fig. 1). The program queries patients about their recent (in the last month) conditions, symptoms, and medication-taking behaviors (including time and frequency of administration). The PEP-NG uses a structured interview process to elicit what patients 


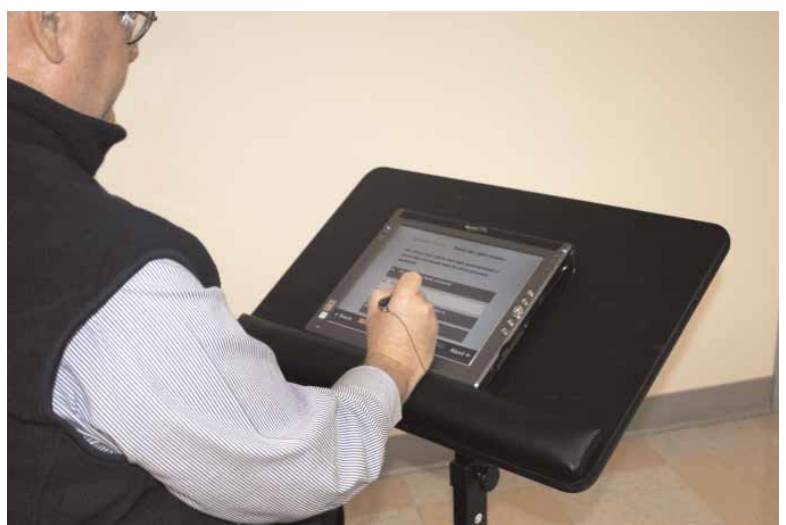

Figure 1: PEP-NG touchscreen interface and stand.

took (prescription and non-prescription medications, supplements, and alcohol) for health maintenance (e.g. vitamins, minerals, herbs, and alcohol) and common health problems (e.g. blood pressure, blood thinning, pain, indigestion, colds, allergies, sleep, and low thyroid). Patient-entered data are analyzed by a PEP-NG rules engine that assesses the risk of the reported adverse self-medication behaviors and delivers a personalized interactive education program that includes Medicine Facts, What You Can Do, animations, and interactive questions tailored to the patient's three behaviors with the highest risk score. ${ }^{19,20}$ A report of the patient's medication behaviors and personalized education is printed for the NP to be reinforced during the primary care visit (see Fig. 2).

The PEP-NG was designed to: (1) be simple to use for both older adults and NP providers; (2) meet the health literacy needs of older adults; (3) elicit patient symptoms, medication taking behaviors, and potential drug interactions before the primary care visit; (4) transform visit waiting time to productive visit time; (5) initiate tailored education based on the patient's specific medication regimen; and (6) support the primary care NP provider's face-toface patient education efforts by reinforcing information generated by the e-health printout. A series of formal usability studies (with both patients and NPs) and a beta trial were completed with the PEP-NG ${ }^{21-23}$ before implementation of a randomized clinical efficacy trial in the primary care setting.

The randomized clinical efficacy trial of the PEPNG was carried out by 11 NP primary care providers with 160 older adults with hypertension meeting independent physical and cognitive function criteria (i.e. visual acuity of at least 20/100 with corrective lenses if needed, independently manage their own shopping, travel arrangements, medication taking, personal finances, and telephone communication as measured on the Instrumental Activities of Daily Living Scale, ${ }^{24}$ and answer 6 of
10 items on the Short Portable Mental Status Questionnaire $^{25}$ ). Each patient participant (in both attention control and intervention groups) interfaced with the PEP-NG in the office and then had a faceto-face visit with the NP once a month for four consecutive months. Intervention participants received the personalized education program described above, the attention control participants received a general education program that explained how BP medicines work and emphasized the need to take BP medicines every day. Compared to patients receiving usual care, patients using the PEP-NG significantly improved their self-medication behaviors as well as their knowledge and self-efficacy for avoiding drug interactions. Among patients who were not at blood pressure (BP) targets upon study entry, systolic $\mathrm{BP}$ and diastolic BP declined in both groups; however, the decrease in the intervention group was more than two-fold greater than that in the attention control group demonstrating both clinical and statistical significance. $^{26}$

The NPs' perspective of their experience with training for the research protocol, recruitment of patient participants, implementing the e-health intervention, and patient response are presented in this article. These data were elicited through openended questions in individual face-to-face tape recorded interviews. Krippendorff's ${ }^{27}$ content analysis approach was used to guide data analysis.

\section{Methods}

The study was approved by the University Institutional Review Board and met all Health Insurance Portability and Accountability Act (HIPAA) regulations. Two practice-based research networks (PBRNs) in Connecticut were the source of study sites: APRNet and the Connecticut Center for Primary Care (CCPC).

The APRNet PBRN is funded by the Agency for Healthcare Research and Quality and administered by the Yale University School of Nursing. The CCPC PBRN is an independent, non-profit corporation established (under state law) by ProHealth Physicians, Inc.

NPs affiliated with the PBRNs were invited to participate via illustrated brochures describing the study. Those interested in participating were provided with an on-site demonstration of the software, tablet, and study materials, and signed consent forms prior to participating in the study. Once recruited, practices were provided with the installation of a wireless access node (meeting HIPAA requirements) at no cost and a free tablet computer (in addition to the study tablet) as incentives. 
Your ID: 896591

Visit: 1

Today you report that you had the following symptoms over the past month:

Pain, Cough, Taste change

Today you report that you have taken the following medicines over the past month:

$\begin{array}{ll}\text { Problem/Symptom } & \text { Medication } \\ \text { Antihypertensives } & \text { Hydrochlorothiazide } \\ & \text { Frequency: when I remember to take it } \\ & \text { Times: 7am } \\ & \text { Spironolactone } \\ & \text { Frequency: when I remember to take it } \\ \text { Times: 7am } & \text { Lisinopril } \\ & \text { Frequency: daily } \\ \text { Timypertensives } & \text { Times: 7pm } \\ & \text { low dose aspirin } \\ & \text { Frequency: daily } \\ \text { Low dose aspirin } & \text { Times: 7am } \\ & \text { Advil } \\ \text { Pain Relievers } & \text { Frequency: daily } \\ & \text { Times: } 9 \mathrm{am}, 12 \mathrm{pm}, 4 \mathrm{pm}, 9 \mathrm{pm}\end{array}$

Report ID: 896591 Visit 1

Medicine Fact:

Blood pressure medicines need to be taken every day to keep your blood pressure down.

What you can do:

Take your blood pressure medicines every day. Keep a list of your medicines in your wallet.

\section{Medicine Fact:}

Aspirin-like pain relievers such as ibuprofen (as in Advil, Motrin) can prevent low-dose aspirin from working.

\section{What you can do:}

Use acetaminophen (as in Tylenol) if you have pain or fever. Take low-dose aspirin at least 2 hours before taking any pain reliever.

\section{Medicine Fact:}

Using aspirin-like medicines such as ibuprofen (in Advil, Motrin) for 3 or more days can keep your blood pressure medicine from working. What you can do:

Use acetaminophen (as in Tylenol) if you have pain or fever. Do not use ibuprofen or naproxen (in Advil, Aleve) for more than a day unless your health care provider checks your blood

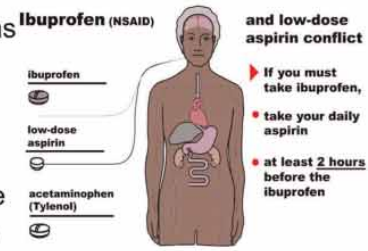
pressure.

Figure 2: Tailored patient education report.

\section{NP training}

NPs were given a two-hour, on-site study training session and offered $\$ 80$ compensation upon completion of training. A member of the research team, who was in a post-masters Adult Nurse Practitioner program, conducted the training. Before the on-site training, NPs logged on to a secure website on the university server to complete 
pre-training knowledge and self-efficacy instruments. $^{28}$ The prescription/over-the-counter (RxOTC) knowledge instrument assessed knowledge of potential adverse self-medication behaviors with anti-hypertensives and commonly used OTC agents. The Rx-OTC self-efficacy instrument measured self-efficacy for avoiding adverse selfmedication behaviors. The Eldercare Self-efficacy instrument $^{29}$ assessed self-efficacy related to communicating with older adults about their medications.

During the training session, NPs tried out both the patient and provider interfaces of the PEP-NG. Ten continuing education units (CEU's) were also offered for reading a packet of ten journal articles related to the information in the PEP-NG and for completing post-training instruments. After reading the articles, they were required to complete post-training knowledge and self-efficacy measurement instruments at two different times: (1) after successfully enrolling their sixth participant (typically three months later), and (2) after their 12th participant (typically 6 months later), respectively. Additional compensation for NPs included \$55 for each participant enrolled (up to 24 participants).

Initially, $20 \mathrm{NPs}$ in 15 primary care sites consented to participate in the study. Five sites and five NPs withdrew soon after the installation of the wireless access nodes for reasons unrelated to the study (including illness, job change, and practice-location change). Fifteen NPs enrolled in the study and completed training. Three additional NPs withdrew from the study after training and before patient enrollment; two of them due to job transfers and one due to illness. An additional NP withdrew after enrolling one participant (who did complete the four visits with the NP). The patient data from this NP were removed from the quantitative analyses but the NP did participate in the qualitative interview. The participating practices were located in two urban centers, three small cities, two suburbs, and two rural areas. Eight of the 12 NPs who completed the study training were salaried, 2 were paid by the number of patients seen, and 2 were paid by the hour. All of the NPs were White, with a mean age of $44.54(\mathrm{SD}=9.71$; range $31-60$ years). The mean NP practice years was 8.4 (SD = 6.67; range 1-23), and the mean nursing practice years was 18.3 (SD = 9.76; range 6-38).

All of the participating NPs were sent an email inquiring if they would be willing to be interviewed regarding their experience with the clinical efficacy trial. A member of the research team (a PhD nursing student experienced in qualitative research and analyses) arranged a time for the interview, at
Table 1: Predetermined set of questions used for NP interviews.

1 On average how many patients do you see a week?

2 How many practitioners work in your office?

3 How are you normally reimbursed by your practice for seeing patients?

4 Do you have your own set of patients that you follow on a regular basis?

5 What type of practice do you work in, i.e. adult medicine, family practice or any specialty area?

6 What was your experience with your training for the PEP?

7 What was your experience with recruiting for the PEP?

8 What did you perceive as barriers to recruitment?

9 What did you like about the PEP

10 What did you dislike about the PEP?

11 Why did you participate in the research?

12 What did you think about your incentive to participate in this research?

13 Were there any other issues with implementing the study in your office?

14 What do you think could improve the program?

15 Is there anything else on your mind regarding the study that you would like to share as we complete this interview?

the convenience of the participant. All interviews took place at the $\mathrm{NP}^{\prime}$ s office. A predetermined set of 15 open-ended questions was used to elicit information regarding what it was like to have participated in the PEP-NG study and their experience with training, recruitment, and implementation of the study in their practice (see Table 1). Upon completion of the interview, the NP was provided with a 25 dollar grocery gift card. Interviews were tape recorded and lasted between 20 to 45 minutes. The interviewer transcribed all the interviews verbatim.

\section{Data analysis}

In order to attain an integrated view of the texts and their specific contexts, Krippendorff's ${ }^{27}$ content analysis method guided the qualitative data analysis. Although both qualitative and quantitative approaches for this research method exist, the qualitative method involves the subjective interpretation of the text through systematically identifying, categorizing, and labeling the patterns and themes in the data. Krippendorff contends that the analyst must examine the texts in context, and inferences are then made to identify core meanings. Emerging from literary theory and widening across multiple disciplines, this approach has enabled many 'to embrace ... the essence of human behavior: talk, conversation ...' (p. 22). ${ }^{27}$

Krippendorff rationalizes that the neutrality of words can be understood from various perspectives 
and advocates for a deeper exploration of texts to understand the underlying message. Hence, data analysis began with reading all transcripts repeatedly to allow immersion. Words and phrases from the transcripts that seemed to have significance were highlighted. Next, notes were taken regarding the researcher's impressions and the context within which the text were examined, in order to identify meanings and draw specific inferences from the transcripts. The coding process involved intense examination and systematic review of the transcripts. Knowledge created from this analysis is based on the participants' individual perceptions and the emergence of content/themes through the researcher analyzing the text.

Polit and Beck ${ }^{30}$ describe methodological rigor through credibility, confirmability, authenticity, dependability, and transferability. Credibility was achieved through tape recording and subsequent verbatim transcription of interviews, adhering to Krippendorff's method for content analysis and providing tables reflecting the process. Confirmability was achieved by two experienced qualitative researchers verifying the coding process and discussing the interpretation of data with emerging themes. Tables were created reflecting the process. Both positive and negative comments reported by the NPs were included, contributing to the authenticity of the data. Adhering to a predetermined set of questions during the interview process and maintaining an open dialogue within the research team contributed to the dependability of the data. ${ }^{31}$

\section{Results}

A total of 10 NPs from 9 different sites agreed to be interviewed. Two of the NPs interviewed did not complete the full study; one withdrew during the initial months of the program, the other changed jobs mid-way through the study. All interviews were conducted after NP training and a minimum of 6 months of enrolling participants. While two NPs were no longer actively involved in the program, the others were either completing final visits of patients currently enrolled or beginning chart reviews of patients who had completed the study.

Five of the offices had only one NP on staff while the others had either two or three. The average number of MDs per office was three, with the numbers ranging from one to seven. The majority (eight) of the practices were internal medicine (IM) with the other two being family practice. Of the IM groups, one practice had a pulmonary specialty and another endocrinology specialty. All of the
NPs interviewed followed their own set of patients at their respective practices. The eight full-time NPs saw between 70-120 patients per week and the two part-time NPs saw between 30 and 50 patients per week. Eight of the NPs were salaried and two were reimbursed on an hourly basis. Six mentioned being provided with yearly bonuses based on productivity or other variables not specified during the interview.

Five distinct themes were identified from the transcripts of the NPs' experience (see Table 2).

\section{Theme one: duty... sense of obligation}

All of the NPs chose to participate in this research because they felt a sense of obligation to their patients, their practice/profession and/or their university alma mater. None were solely driven by the incentive piece, although about half did mention that it was a nice added bonus. One person felt that her participation was 'a good way to keep nurse practitioners visible as healthcare providers.' A former University of Connecticut graduate described the reputation of the principal investigator (PI) as her impetus, 'her research is always good research that you can translate into the office.' The majority felt that the program sounded interesting and their patients could benefit from it. They liked the 'interactive' nature of the tablet and considered the experience would be a 'different' and an 'innovative' way to help patients get information. It was also viewed as an opportunity 'to help them [the patients] to make better healthcare decisions,' especially the targeted older age range since 'no matter how old these patients get to be, they are always interested in learning about their meds.' One NP strongly believed that the program could 'empower the patients that I see, to allow them to be more cognizant of what's out there...' Participation was also seen as an opportunity to 'improve the way I practice.'

\section{Theme two: learning together}

The majority of NPs discussed a significant learning curve at the beginning of the process. They acknowledged that using the tablet with the first two or three patients took them [the $\mathrm{NP}^{\prime} \mathrm{s}$ ] a longer time to complete, but did experience feeling more comfortable as time elapsed. According to the NPs, the patients also experienced a similar process. One expressed the following about the patients, 'Once they understood how to use it, everybody reacted positively.' One NP stated, 'I wish I had the opportunity to run through the entire program computer module [again] before giving it to patients.' She felt that 
Table 2: Process of theme development.

\begin{tabular}{|c|c|c|c|}
\hline $\begin{array}{l}\text { Question } \\
\text { number }\end{array}$ & Participant quote & Category & Theme derived \\
\hline 11 & $\begin{array}{l}\text { 'Her research is always good ... you can translate [it] } \\
\text { into the office.' (Interview \#3) }\end{array}$ & For school & $\begin{array}{l}\text { Duty ... sense of } \\
\text { obligation }\end{array}$ \\
\hline 11 & 'something different for my patients.' (Interview \#2) & For my patients & \\
\hline 11 & $\begin{array}{l}\text { 'something to improve the way I practice as well as } \\
\text { empower the patients...' (Interview \#7) }\end{array}$ & $\begin{array}{l}\text { For my practice and } \\
\text { patients }\end{array}$ & \\
\hline 11 & $\begin{array}{l}\text { 'a good way to keep nurse practitioners visible as } \\
\text { healthcare providers.' (Interview \#5) }\end{array}$ & For my profession & \\
\hline 11 & $\begin{array}{l}\text { 'Patients are eager for this information ... this was an } \\
\text { innovative way to try and get the information out to } \\
\text { them ...' (Interview \#9) }\end{array}$ & For my patients & \\
\hline 9 & $\begin{array}{l}\text { 'The patients really enjoyed it and I learned a lot too' } \\
\text { (Interview \#6) }\end{array}$ & Dual learning & Learning together \\
\hline 10 & $\begin{array}{l}\text { 'It was a learning experience on both parts [patient and } \\
\text { provider]' (Interview \#7) }\end{array}$ & Learning Curve & \\
\hline 13 & $\begin{array}{l}\text { '[She] walked me through it-observed me as I was } \\
\text { doing it- and it was a reassurance.' (Interview \#9) }\end{array}$ & Help Provided & \\
\hline 9 & $\begin{array}{l}\text { '... once they understood how to use it- everyone } \\
\text { reacted positively and said they liked doing it.' } \\
\text { (Interview \# 4) }\end{array}$ & $\begin{array}{l}\text { Dual learning/ } \\
\text { learning curve }\end{array}$ & \\
\hline 6 & $\begin{array}{l}\text { 'The support was very good ... anytime I had a } \\
\text { problem I could always get somebody.' (Interview } \\
\text { \#10) }\end{array}$ & Help provided & \\
\hline 7 & 'It took a long time [recruiting patients].' (Interview \#1) & Recruitment & Recruitment hurdles \\
\hline 7 & $\begin{array}{l}\text { '[Recruitment] adds yet another time demand in an } \\
\text { already very busy schedule.' (Interview \#8) }\end{array}$ & Recruitment & \\
\hline 10 & $\begin{array}{l}\text { 'I would come in an hour early on a day when I knew I } \\
\text { had a PEP study coming in ... on my own personal } \\
\text { time and did this.' (Interview \#9) }\end{array}$ & Personal - NP & \\
\hline 7 & $\begin{array}{l}\text { 'With other obligations that individuals had, the time } \\
\text { commitment proved to be a problem.' (Interview \#7) }\end{array}$ & Personal - patient & \\
\hline 10 & $\begin{array}{l}\text { 'I have time constraints all the time ... it's a way of life } \\
\text { for internal medicine and primary care' (Interview \#3) }\end{array}$ & Personal - NP & \\
\hline 10 & $\begin{array}{l}\text { 'There were a lot of little technical things / } \\
\text { issues ... that's what I didn't like about the } \\
\text { program ... the time [they took]' (Interview \#10) }\end{array}$ & Technical difficulties & Logistical obstacles \\
\hline 10 & $\begin{array}{l}\text { 'IT issues ... time on the phone. That took up a lot more } \\
\text { time than the actual study' (Interview \#5) }\end{array}$ & Technical difficulties & \\
\hline 13 & $\begin{array}{l}\text { 'the technical piece. That was bothersome for me ... like } \\
\text { one afternoon I spent an hour on the phone with the } \\
\text { tech guy and he was trying to help me figure it out.' } \\
\text { (Interview \#2) }\end{array}$ & Technical difficulties & \\
\hline 13 & $\begin{array}{l}\text { 'It was too far a distance from the rooms to waiting } \\
\text { area, so we used an exam room instead' (Interview \#8) }\end{array}$ & Building geography & \\
\hline 13 & $\begin{array}{l}\text { 'Our office waiting room area is very congested at times } \\
\text { and so I had to use the kitchen and had to do it } \\
\text { around lunch shifts' (Interview \#7) }\end{array}$ & Space & \\
\hline 14 & $\begin{array}{l}\text { 'audio with the video movies because people don't } \\
\text { know when it ends.' (Interview \#10) }\end{array}$ & Study changes & Future possibilities \\
\hline 14 & $\begin{array}{l}\text { 'I would love to see something like this at the senior } \\
\text { center because these are people who are looking for } \\
\text { different ways to improve their health. (Interview \#7) }\end{array}$ & Other sites & \\
\hline 8 & $\begin{array}{l}\text { 'There should have been someone like you here doing } \\
\text { recruitment. I don't have time to do it.' (Interview \#8) }\end{array}$ & Additional help & \\
\hline 14 & $\begin{array}{l}\text { 'I got positive feedback that patients are retaining the } \\
\text { information. It was very gratifying.' (Interview \#5) }\end{array}$ & $\begin{array}{l}\text { Satisfied } \\
\text { participants }\end{array}$ & \\
\hline 15 & $\begin{array}{l}\text { 'I enjoyed participating and I would do it again.' } \\
\text { (Interview \#2) }\end{array}$ & $\begin{array}{l}\text { Satisfied } \\
\text { participants }\end{array}$ & \\
\hline
\end{tabular}


this would have made it easier to understand some of the questions that patients asked once they started the different modules.

The support provided throughout the program was discussed as valuable and helpful to the learning process, 'anytime I had a problem I could always get somebody.' While they did discuss frequently needing technical assistance, they also reported never feeling alone, 'there was always someone if something goes wrong- like back up.' The research team was 'very organized and efficient,' and the majority of NPs were impressed with the people helping the PI. They were able to provide 'reassurance' and contributed to the overall feeling of encouragement throughout the study. The PI was described as 'accessible' and 'very helpful.' Another stated, 'If I had trouble, she was very prompt. Like I had a problem yesterday and she emailed me by that afternoon.' This also played an integral part in the overall learning process and satisfaction of the NPs.

\section{Theme three: recruitment hurdles}

All of the NPs cited hurdles throughout the process of implementing the research-related tasks of the study. While the training aspect was rarely brought up as time consuming, the recruitment of participants was repeatedly expressed as a time intensive process. Although the offices were provided with brochures and posters to assist with patient recruitment, all practices needed to take additional measures to recruit participants. 'Although people would take the pamphlets home, we needed to follow-up on them.' Another practice mailed out letters to all eligible participants in an effort to increase awareness, 'I think the biggest hurdle with the recruitment of patients was just trying to get the word out and make patients aware.' Even though some responded to seeing the posters that were displayed, one NP stated, 'it [recruitment] adds yet another time demand in an already very busy schedule... we needed some active intervention on my part to get the number of people that we've pulled in ...' One NP very honestly stated, 'I just forget to get it [the brochure] or [forget to] ask patients sometimes.'

Another had a younger clientele and the study targeted older adults over the age of 60 . This NP relied on the other doctors in the practice to distribute recruitment brochures to patients. She used reminders on charts for the doctors, but still struggled. She described it as a 'painful process ... just trying to get the doctors to do one more thing.' In the end, this NP discontinued participation in the study.
Recruitment issues were also complicated by the targeted age of the study population. Even though the recruitment brochures stated that patients did not need to know how to use a computer and showed a photograph of an older aged patient using the touchscreen tablet in the office, some older adults felt nervous about the technical piece, 'they just kept saying that they didn't know how to use computers.' Another commented, 'A lot of older people were very frightened by the computer initially.' Those people between ages 60-65 that still worked also had a problem with the time commitment that the study entailed. Certain older patients had transportation issues, because of their inability to drive. All of these issues, contributed to the NPs frustration with recruiting study participants.

The NPs all spent 'personal time' on the study as well and this limited the number of participants who could be recruited. One NP did all study visits during her lunch break so that she could be available to assist the participants if they had any problems. Another stated that patients were scheduled, 'at a down time so that I could answer questions if they had any.' One NP would come into work one hour early on the days that she knew she had a study participant, in order to ensure that everything would be ready and working correctly for the patient. Another commented that 'less than half the time could the visit be combined with a reimbursable visit' and cited the length of time for the PEP-NG visit as a main reason for this. Other reasons that the study visits could not be combined with a reimbursable visit were that some patients belonged to other doctors in the practice and other times the study visits occurred in between their regularly scheduled visits.

\section{Theme four: logistical obstacles}

The study relied on web-based technologies and use of the touchscreen-enabled tablet computer. All of the NPs discussed technical problems as contributing to the time-consuming aspect of the study. While a few mentioned hardware issues (problems with starting the wireless node/tablet, the printer not printing, issues with the charging plug), the majority of concerns dealt with primary care office connectivity to the Internet; 'I did have a problem trying to get a live human being [for practice IT assistance] on the phone.' On a number of occasions (six out of 640 visits, according to the study IT problem log) a patient was already in the office and after numerous failed attempts to fix the problem, the patient would be sent home and the visit rescheduled. The time spent searching for the problem and then on the 
phone with practice and/or PEP-NG project IT personnel were cited as a 'huge frustration' and 'very stressful' for certain NPs. Overall, eight of the NPs interviewed cited time-consuming technical difficulties as part of the problem with implementing the study in their offices.

While the initial intent of the PEP-NG was for it to be completed in the waiting room, prior to the primary care visit, the majority of the sites modified this to meet their specific workflow needs. A few mentioned the geography of their buildings as part of the problem. One NP had her office on the second floor and the waiting room on the first floor and felt '... they can't do it alone without someone being able to come out to answers questions...' Another also stated that it was 'too far a distance from my room to the waiting room.' In another practice, the doctors decided 'it [the waiting room] wasn't where they wanted them to do it because it wasn't quiet enough for people to concentrate.' An alternate space was needed for participants and it was usually a free exam room. Offices not in use or the kitchen/ lunch break areas were also utilized to accommodate patients. And because of the amount of time that it took patients to complete each module, finding space became an issue.

\section{Theme five: future possibilities}

One NP strongly felt that the e-health intervention was not a good fit for primary care. This NP was also the one who expressed frustration because the waiting room and office were on different floors and the practice had Internet connection problems. All of the other NPs saw e-health's potential and made positive suggestions which could facilitate its use in practice. The majority of NPs were excited 'to see their [patients'] growth' in response to their PEP-NG use. One commented that she was, '... really surprised at how well my patients adapted to using the computer.' Three suggested it could be used in places like senior centers, longterm healthcare facilities or 'somewhere like the mall where patients can sit down and run through it on their own.'

The experience was described as 'very gratifying' by one NP. Other comments included: 'I loved that my patients got to take something away with them each time,' 'People got excited about learning something,' and '[I] received positive feedback that patients are retaining that information.' NPs suggested that audio be added to the animations and played simultaneously with the video 'because people had trouble realizing when it [the video] ended.' A next button with audio prompt was also proposed by four NPs in order to move the participant along the module with more ease.

All of the NPs expressed concern about the participants who were in the control group. They felt this group was provided with less feedback from the program (than those in the intervention group) and had more questions for the NP during the visit after interfacing with the PEP-NG. One NP mentioned that 'the control group obviously doesn't get as much out of it as the study group.' Another adamantly stated 'if people are going to donate their time, they need to be getting something out of it.' Since some module content (e.g. interactive knowledge questions) is repetitive and patients returned for four consecutive visits, some of the NPs felt that without feedback, control patients would 'have no idea if they were putting in the right or wrong answers.' Other items mentioned that could improve the study included: having a member of the research team help with recruiting participants, shortening the length of the embedded research instruments, and eliminating some of the surveys that the NPs had to complete throughout the study.

\section{Limitations and discussion}

It should be noted that the interviewer did feel that she encountered extremes during the NP interviews. One site in particular experienced excessive difficulty with recruiting and the geography of the building caused problems with implementation, causing the NP to be quite dissatisfied with her experience (although this NP did complete the study). Of note, this NP also chose at the onset to have all her incentives be given to the practice. The other participants chose to retain the incentives for personal use and while financial incentives were not mentioned as drivers for NPs to participate, this could be viewed as a limitation of the study. Another limitation to consider is that certain NP interviews were conducted after all patient data were completed, while others were interviewed prior to being fully done with the study. Two NPs dropped out of the study before completing recruitment - data from these NPs can be considered a limitation. However, their experiences offer valuable insight into the barriers to implementing ehealth interventions in the workflow of primary care. Finally, the small sample size of NPs and their gender and racial homogeneity are study limitations.

Research incorporating NPs is necessary and vital to improving primary health care for older adults. ${ }^{32}$ All of the NPs who participated in this qualitative study were interested in providing their patients 
with a new and innovative way to learn. Although NPs had an initial learning curve, the majority completed the study and found it to be helpful for both their patients and themselves. Qualitative interviews with 12 intervention older adult participants also demonstrated high satisfaction with the PEPNG. ${ }^{33}$ In fact, nearly all older adults interviewed expressed a desire to be recruited for similar future programs. Interestingly, a recurring theme from the patient data was the importance of the NP in their learning process. Mean scores on a nine-item satisfaction instrument were significantly higher $(t$ $(132)=2.04, P=0.0431)$ on visit four in the intervention group $(n=71)$ compared to patients in the control group $(n=64)$ also suggesting a high degree of satisfaction with the PEP-NG intervention. The intervention group also had higher mean intent to change scores (a six-item scale) on visit four ( $t$ $(132)=2.16, P=0.033) .{ }^{26}$

Quantitative measures with both patients and NPs showed statistically significant increases in knowledge and self-efficacy regarding adverse selfmedication behaviors. Older adults in the intervention arm of the study achieved large effect sizes in their increases from visit one to visit four in mean self-medication knowledge (paired $t(73)=6.26$, $P<0.0001)$ and mean self-medication self-efficacy (paired $t(73)=10.38, P<0.0001$ ) while there were no significant changes in these measures in the control group. ${ }^{26} \mathrm{NPs}$ showed statistically significant increases in their knowledge (paired $t=2.94, P=$ 0.014 ) and self-efficacy (paired $t=2.49, P=0.016$ ) regarding patient's avoiding potential adverse selfmedication behaviors as well as a statistically significant increase in their self-efficacy for communicating with older adults about medications (paired $t=$ 2.37, $P=0.039) .{ }^{28}$ These measures support the NPs' qualitative views of the patient and NP experience with the PEP-NG.

The 2010 US Health and Human Services National Action Plan to Improve Health Literacy emphasizes that health information must be 'accurate, accessible and actionable. $^{34}$ The targeted and tailored health information provided by the PEP-NG meets these guidelines for both patients and primary care providers at the point of care. In primary care settings, faceto-face provider-patient time is limited ${ }^{35}$ and, as with computer-based decision support programs, ${ }^{36}$ e-health programs must also support provider education of patients in a time-efficient manner. Koppel et al. ${ }^{37}$ emphasized that the failure to 'focus on the organization of work' (p. 1202) in which a technology is to be used, is a major impediment to provider adoption. Future research will involve a translational study in which the PEP-NG will be incorporated into routine workflow of primary care by removing the 'research-only'-based content and allowing patients to utilize the program either in their homes or the primary care office. This will remove the recruitment hurdles and some of the logistical barriers imposed by the research design and decrease the amount of time taken by NPs to implement the e-health intervention.

The majority of the NPs were able to look beyond the study inconveniences and see the potential benefits of the PEP-NG for their practice and their patients. The overall sentiments of the NPs were positive and suggested that incorporating technology into the patient visit could both enhance the patient learning process and improve communication. Summarized by one of the NPs, 'Almost every patient has said at least once "I didn't know that" and that is what I liked about the study.'

\section{Acknowledgments}

This research was supported in part by a grant from the National Institutes of Health (National Heart Lung and Blood Institute): Grant R01 HL084208. Trial Registration (clinical trials.gov) Identifier: NCT00201201. The authors thank Dr Cheryl Beck for her guidance in the qualitative methods used in this study.

\section{Conflicts of interest statement}

The University of Connecticut granted an exclusive license for the PEP-NG to AdhereTx Corporation on 25 August 2009. The University of Connecticut and Patricia J. Neafsey are shareholders of AdhereTx. Jessica Planas and Elizabeth Anderson have no conflicts of interest.

\section{References}

1. National Research Council (US). A population-base policy and systems change approach to prevent and control hypertension: consensus report. Washington, DC: National Academies Press; 2010. [cited 2012 May 15]. Available from http://books.nap.edu/ open-book.php?record_id=12819\&page=R1.

2. Tarn DM, Paterniti DA, Kravitz RL, Fein S, Wenger NS. How do physicians discuss medication reviews? J Gen Intern Med 2009;24(12):1296-302.

3. National Research Council (US). Preventing medication errors: quality chasm series. Washington, DC: National Academies Press; 2006 [cited 2012 May 15]. Available from http://www.nap.edu.

4. Bennet IM, Chen J, Soroui JS, White S. The contribution of health literacy to disparities in self-rated health status and preventive health behaviors in older adults. Ann Fam Med 2009;7:204-11.

5. U.S. Department of Education. The health literacy of America's Adults: results from the 2003 National Assessment of Adult Literacy. Washington, DC: USDE Institute of Education Sciences, Education Statistics. 2006. 
6. Geller BM, Skelly JM, Dorwaldt AL, Howe KD, Dana GS, Flynn BS. Increasing patient/physician communications about colorectal cancer screening in rural primary care practices. Med Care 2008; 46(9):S36-S43.

7. Mark TL, Fortner B, Johnson G. Evaluation of a tablet PC technology to screen and educate oncology patients. Support Care Cancer 2008;16:371-378. doi: 10.1007/s00520-0070312-1.

8. Rogausch A, Sigle J, Seibert A, Thuring S, Kochen MM, Himmel W. Feasibility and acceptance of electronic quality of life assessment in general practice: an implementation study. Health Quality Life Outcomes, 2009;7:51. doi: 10.1186/ 1477-7525-7-51.

9. Stevens VJ, Glasgow RE, Toobert DJ. One year results from a brief computer-assisted intervention to decrease consumption of fat and increase consumption of fruits and vegetables. Prev Med 2003;36: 594-600.

10. Loftus LA, Weston V. The development of nurse led clinics in cancer care. J Clin Nurs 2001;10:215-20.

11. Jeanfreau S. Group intervention to improve diabetes care - a program utilizing group visits by a nurse practitioner to improve outcomes for the medically underserved in diabetes care. Southern Online J Nurs Res 2007;8(2):1.

12. Ortiz J, Wan TT, Meemon N, Paek SC, Agiros A. Contextual correlates of rural health clinics' efficiency: analysis of nurse practitioners' contributions. Nurs Econ 2010;28(4):237-44.

13. Cooper J, Loeb SJ, Smith CA. The primary care nurse practitioner and cancer survivorship care. J Am Acad Nurse Pract 2010;22:394-402.

14. Barton AJ, Baramee J, Sowers D, Robertson KJ. Articulating the value-added dimension of NP care. Nurse Pract 2003;28:34-40.

15. Dick K, Frazier SC. An exploration of nurse practitioner care to homebound frail elders. J Am Acad Nurse Pract 2006;18:325-34. doi: 10.111/j.17457599.2006.00140.x.

16. Allen JK, Blumenthal RS, Margolis S, Young DR, Miller ER, III, Kelly K. Nurse case management of hypercholesterolemia in patients with coronary heart disease: Results of a randomized clinical trial. Am Heart J 2002;144:678-86.

17. Mason CM. The nurse practitioner's role in helping patients achieve lipid goals with statin therapy. J Am Acad Nurse Pract 2005;17(7):256-62.

18. Allen JK, Himmelfarb CR, Szanton SL, Bone L, Hill MN, Levine DM. COACH trial: a randomized controlled trial of nurse practitioner/community health worker cardiovascular risk reduction in urban community health centers: rational and design. Contemp Clin Trials 2011;32(3):403-11. doi: 10.1016/ j.cct.2011.01.001.

19. Strickler Z, Rauh C, Lin C, Neafsey PJ. Educating older adults to avoid harmful self-medication. J Health Commun 2008;1:110-28.

20. Neafsey PJ, Anderson E, Coleman C, Lin CA, M'lan CE, Walsh S. Reducing adverse self-medication behaviors in older adults with the next generation Personal Education Program (PEP-NG): design and Methodology. Patient Prefer Adherence 2009;3: 323-34. PMCID: PMC2792870.

21. Lin CA, Neafsey PJ, Strickler Z. Usability testing by older adults of a computer-mediated health communication program. J Health Commun 2009; 14(2):102-18. PMCID: PMC2964868.

22. Lin C, Lin CA, Neafsey PJ, Anderson E. APRN usability testing of a tailored computer-mediated health communication program. Comp Info Nsg 2010;28(1): 32-41. PMCID: PMC2871320.

23. Neafsey PJ, Anderson E, Peabody S, Lin C, Strickler Z, Vaughn K. Beta testing of a network-based health literacy program tailored for older adults with hypertension. Comput Inform Nurs 2008;26: 311-19.

24. Lawton MP, Brody EM. Assessment of older people: self-maintaining and instrumental activities of daily living. Geronotologist 1969;9:179-86.

25. Pfeiffer E. A short portable mental status questionnaire for the assessment of organic brain deficit in elderly patients. J. Am Geriatr Soc 1974; 23:433-41.

26. Neafsey PJ, M'Lan CE, Ge MM, Walsh S, Lin CA, Anderson E. Reducing adverse self-medication behaviors in older adults with hypertension: results of an e-health clinical efficacy trial. Special Technology and Ageing Issue, Ageing Int 2011;36(2):159-191. Online first, 08 December. doi: 10.1007/s12126-0109085-9. PMCID: PMC3092917.

27. Krippendorff K. Content analysis - an introduction to its methodology. 2nd ed. Thousand Oaks, CA: Sage Publications, Inc; 2004.

28. Neafsey PJ, Anderson E. Results of the implementation of an e-health intervention in primary care on nurse practitioner knowledge and self-efficacy related to adverse self-medication practices in older adults with hypertension. 2012. Unpublished manuscript.

29. Shellman J. Reliability and validity testing of the Eldercare Cultural Self-Efficacy Scale. Int J Nurs Educ Scholarsh 2006;3(1) [cited 2012 May 15] Available from http://www.bepress.com/ijnes/ vol3/iss1/art9.

30. Polit DF, Beck CT. Nursing research: generating and assessing evidence for nursing practice. New York: Wolters Kluwer/Lippincott Williams \& Wilkins; 2008.

31. Granheim UH, Lundman B. Qualitative content analysis in nursing research: concepts, procedures and measures to achieve trustworthiness. Nurse Educ Today 2004;24:105-12.

32. Moote M, Krsek C, Kleinpell R, Todd B. Physician assistant and nurse practitioner utilization in academic medical centers. Am J Med Qual 2011;26(6): 452-60.

33. Alicea-Planas J, Neafsey PJ, Anderson E. A qualitative study of older adults and computer use for health education. J Commun Healthcare 2011; $4(1): 38-45$.

34. National Action Plan to Improve Health Literacy. Washington, DC: Department of Health and Human Services (US), Office of Disease Prevention and Health Promotion; 2010 [cited 2012 May 15]. Available from http://www.health.gov/communication/hlactionplan/.

35. Hing E, Cherry DK, Woodwell DA. National ambulatory medical care survey: 2004 summary. Advance data from vital and health Statistics. No. 374, Hyattsville, MD: National Center for Health Statistics; 2006.

36. Garg AX, Adhikari NK, McDonald H, Rosas-Arellano MP, Devereaux PJ, Beyene J, et al. Effects of 
computerized clinical decision support systems on practitioner performance and patient outcomes. A systematic review. JAMA 2005;293(10): 1261-3.

\section{Author information}

Jessica Alicea-Planas, RN, MPH, PhD CHES is an assistant professor in the School of Nursing at the Fairfield University in Fairfield, CT. She has worked as a community health nurse in underserved areas for over a decade and is certified health education specialist (CHES). She received her undergraduate, masters and doctoral nursing degrees from the University of Connecticut and her master's in public health is from Southern Connecticut State University. Her primary area of interest encompasses Latino health disparities with a focus on chronic disease management, health literacy and health education.

Patricia Neafsey, PhD is professor, Center for Health Intervention and Prevention and School of Nursing at the University of Connecticut. She is a pharmacologist and author on over 100 peer reviewed publications and
37. Koppel R, Metlay JP, Cohen A, Abaluck B, Localio AR, Kimmel SE, et al. Role of computerized physician order entry systems in facilitating medication errors. JAMA 2005;293(10):1197-203.

25 computer-assisted instructional programs in pharmacology. She was principal investigator on grants from the University of Connecticut Research Foundation, the Donaghue Medical Research Foundation, and the NIH National Heart Lung and Blood Institute that funded the development and testing of the Next-Generation Personal Education Program (PEP-NG), an $e$-health intervention to improve patient adherence to antihypertensive regimens and reduce adverse self-medication behaviors. The University of Connecticut granted an exclusive license for the PEP-NG to AdhereTx Corporation, a provider of web-based solutions that facilitate patient data collection and automate coordination of care for medication management in patients with chronic diseases. Dr. Neafsey serves as principal scientist for AdhereTx. 
Copyright of Journal of Communication in Healthcare is the property of Maney Publishing and its content may not be copied or emailed to multiple sites or posted to a listserv without the copyright holder's express written permission. However, users may print, download, or email articles for individual use. 